\title{
Evaluation of morphology of cataracts in patients with NIDDM
}

\author{
ChopraA. $^{1}$, Sharma A. ${ }^{2}$ \\ ${ }^{1}$ Dr. Amit Chopra, Associate Professor, ${ }^{2}$ Dr. Amit Sharma, Associate Professor; both authors are attached with \\ Department of Ophthalmology, MM Medical College, Solan, Himachal Pradesh, India.
}

Corresponding Author: Dr. Amit Sharma, Associate Professor, Department of Ophthalmology, MM Medical College, Solan, Himachal Pradesh, India. E-mail: rkchopra519@gmail.com

\begin{abstract}
Purpose: Various population-based studies have shown the association between diabetes and cataracts and have defined various risk factors for the development of cataract. There is evidence that the risk of cataract increases with increasing duration of diabetes and severity of hyperglycaemia. This paper provides an overview of the morphology of cataracts among NIDDM patients of Himachal area of north India. Material \& Methods: This study was conducted in department of ophthalmology in MMMC \& Hospital, Kumarhatti, Solan. 100 eyes of 62 patients in the age range of 50- 80 years with pre existing diabetes \& cataract were recruited from Nov 17 to Oct 18 in prospective study. The morphology of cataract was categorised as per locs 3 protocol in which clinical assessment with slit lamp or grading performed on retro illumination photographs. Results: Out of 100 eyes, 21 eyes with posterior subcapsular cataract, 16 eyes with cortical, 9 eyes with nuclear, 54 eyes with mixed component. Thirty-eight patients had bilateral cataract. After statistical analysis, it was seen that duration of diabetes \& HbA1c levels are not significantly correlated with grades of cataract. However, the prevalence of 54\% in case of mixed cataract in type 2 diabetes is high as compared to the monotype. Conclusion: In this study it was found that duration of non-insulin dependent diabetes mellitus and HbAlC levels are not statistically correlated with the grades of cataract. Mixed cataracts were however more common than any particular morphology of cataract.
\end{abstract}

Keywords: NIDDM, Glycosylated haemoglobin, Posterior subcapsular cataract

\section{Introduction}

Cataract contributed to a worldwide $33.4 \%$ of all blindness and $18.4 \%$ of all moderate \& severe vision impairmentand also has been recognized to be the most significant cause of unilateral \& bilateral blindness affecting approximately 18 million people globally [17]. In India various studies have shown that cataract constitutes $62-77 \%$ of total cases of avoidable blindness and has been reported to be responsible for $50-80 \%$ of bilateral blind in the country $[8,9]$. Increasing sedentary lifestyles \& increasing prevalence of obesity leads to increase in the number of patients with NIDDM [10].

Hamilton AM et al found that $20 \%$ of all cataract procedures are estimated to be performed on diabetic patients [11]. Various epidemiological studies have demonstrated that cataracts are the most common cause of visual impairment in older onset diabetics $[12,13]$. Rate of cataract is correspondingly high in cases with

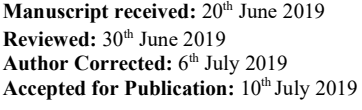

NIDDM as compared to IDDM and also cataract develops at an earlier age and 2-5 times more frequent in patients with diabetics $[14,15]$. Janghorbani \& Amini evaluated that incidence of cataract formation is high in type 2 diabetes mellitus[16].

This study was aimed to evaluate the association of morphology of cataract with the duration of non insulin dependent diabetes mellitus and relation of HbA1c levels in a cohort of diabetic patients who had presented in eye OPD with cataracts and the findings are reported in the paper.

\section{Methods}

Type of study: Prospective study

Duration of the study: The duration of the study was one year. 100 eyes of 62 patients in the age range of 5080 years with pre-existing diabetes and cataract were recruited from November 2017 to October 2018 in a prospective study. 
Original Research Article

The morphology of cataract was categorized as per LOCS 3 protocol in which clinical assessment with slit lamp or grading performed on retro illumination photographs[17].

As per the guidelines of Institutional Ethics committee the study was conducted in the Department of Ophthalmology, MM Medical College, Solan and also had obtained consent from the patient.

A diabetic patient was defined as one who had fasting serum glucose concentration of equal to or more than $126 \mathrm{mg} / \mathrm{dl}$ or who had greater than $200 \mathrm{mg} / \mathrm{dl}$ when measures 2 hrs after meal.

The duration of diabetes was taken as the period from the first diagnosis of diabetes to the day of examination for cataract as informed by the patient.

All the patients underwent ophthalmologic examination including visual acuity assessment and evaluation using slit lamp biomicroscopy and dilated fundus examination using $90 \mathrm{D}$ lens and indirect ophthalmoscopy.

\section{Inclusion criterion}

- Age $>40$ years

- Patients with clear cornea

- Patients with adequate pupillary dilatation

\section{Exclusion criterion}

- Patients with IDDM

- Patients with compromised cornea

- Patients with inadequate pupillary dilation

\section{Statistical analysis}

Apart from the duration, HbAlc levels at the time of presentation were also taken into consideration and statistically analysed with morphology of cataract. Statistical analysis was performed using the spss software package version 16 .

Significant difference between grades of cataract with duration of NIDDM in years, HbA1c levels were analysed by chi- square test. $\mathrm{P}$ value less than 0.05 was considered as significant.

\section{Results}

After statistical analysis, it was seen that duration of diabetes is not significantly correlated with grades of cataract ( $p$ value is 0.40 ). Also HbA1c levels are not significantly correlated with grades of cataract ( $\mathrm{p}$ value is 0.26 ). However, the prevalence of $54 \%$ in case of mixed cataract in type 2 diabetes is high as compared to the monotype.

Table-1: Frequency of morphology of cataract with respect to duration of diabetes.

\begin{tabular}{|c|c|c|c|c|c|c|c|c|c|c|c|c|c|c|c|c|}
\hline \multirow{2}{*}{$\begin{array}{l}\text { Duration } \\
\text { In years }\end{array}$} & \multicolumn{5}{|c|}{ Cortical-16 eyes } & \multicolumn{4}{|c|}{ Psc-21eyes } & \multicolumn{6}{|c|}{ NO/NC- 9 eyes } & \multirow{2}{*}{$\begin{array}{c}\text { Mixed } \\
- \\
\text { 54eyes }\end{array}$} \\
\hline & $\mathrm{C}_{1}$ & $\mathrm{C}_{2}$ & $\mathrm{C}_{3}$ & $\mathrm{C}_{4}$ & $\mathrm{C}_{5}$ & $\mathrm{P}_{1}$ & $\mathrm{P}$ & & $\begin{array}{l}\mathrm{P} \\
5\end{array}$ & $\begin{array}{c}\mathrm{NO} \\
1 \\
\mathrm{NC} \\
1\end{array}$ & $\begin{array}{c}\mathrm{NO} \\
2 \\
\mathrm{NC} \\
2\end{array}$ & $\begin{array}{c}\mathrm{NO} \\
3 \\
\mathrm{NC} \\
3\end{array}$ & $\begin{array}{c}\mathrm{NO} \\
4 \\
\mathrm{NC} \\
4\end{array}$ & $\begin{array}{c}\mathrm{NO} \\
5 \\
\mathrm{NC} \\
5\end{array}$ & $\begin{array}{c}\mathrm{NO} \\
6 \\
\mathrm{NC} \\
6\end{array}$ & \\
\hline $0-5$ & & 2 & & 3 & & 3 & 4 & & & & 1 & 1 & & & & 16 \\
\hline $6-10$ & 1 & 3 & 1 & 2 & & 1 & 3 & & & & 2 & 1 & 1 & & & 28 \\
\hline $11-14$ & & 1 & 2 & & & & 1 & & & & 1 & & & & & 6 \\
\hline $\begin{array}{l}15 \text { and } \\
\text { above }\end{array}$ & 1 & & & & & & 1 & & & & & 1 & & & L & 4 \\
\hline
\end{tabular}

Out of 100 eyes, 21 eyes with posterior subcapsular cataract, 16 eyes with cortical, 9 eyes with nuclear, 54 eyes with mixed component and out of 54 eyes, 34 eyes with both ns and psc component and 20 eyes with both ns and cortical component. Thirty eight patients had bilateral cataract. 
Original Research Article

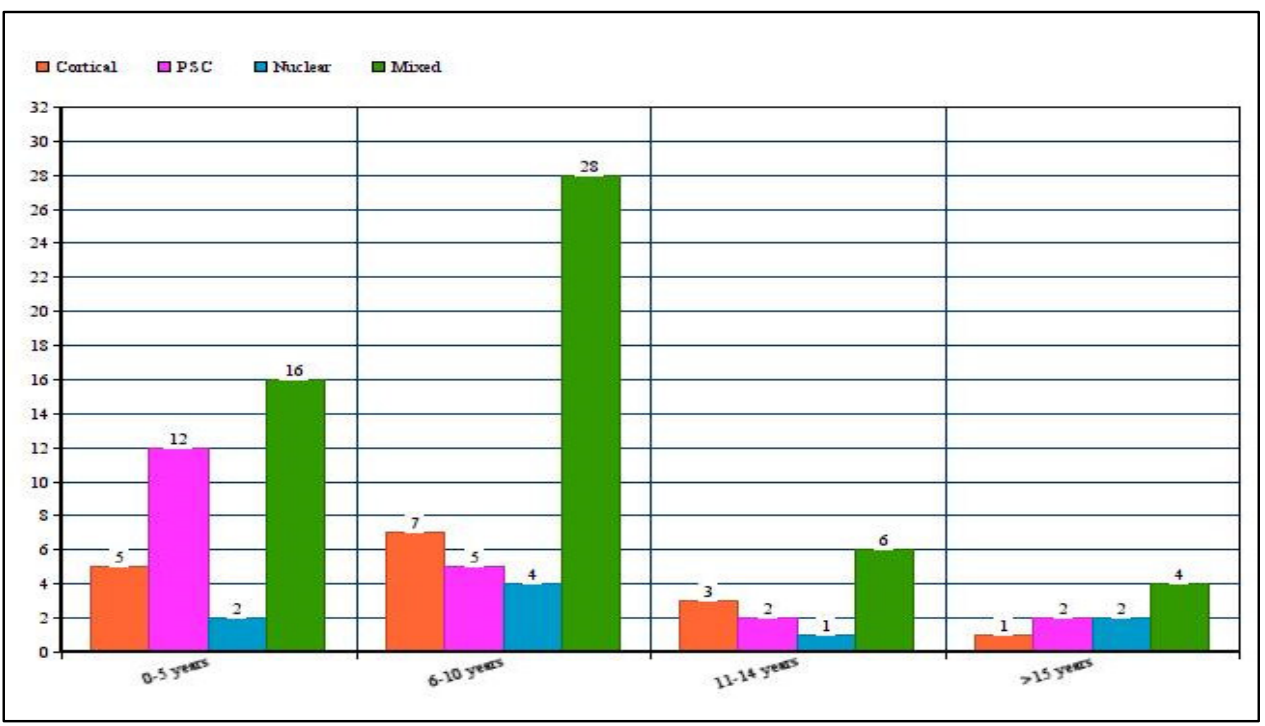

Figure 1: Frequency of morphology of cataract with respect to duration of diabetes.

Table-2: Frequency of cataract morphology with respect to HbA1c levels.

\begin{tabular}{|c|c|c|c|c|c|c|c|c|c|c|c|c|c|c|c|c|c|}
\hline HbA1c & \multicolumn{5}{|c|}{ cortical } & \multicolumn{5}{|c|}{ psc } & \multicolumn{6}{|c|}{$\mathrm{NO} / \mathrm{NC}$} & Mixed \\
\hline & $\mathrm{C}_{1}$ & $\mathrm{C}_{2}$ & $\mathrm{C}_{3}$ & $\mathrm{C}_{4}$ & $\mathrm{C}_{5}$ & $\mathrm{P}_{1}$ & $\begin{array}{l}\mathrm{P} \\
2\end{array}$ & $\begin{array}{l}\mathrm{P} \\
3\end{array}$ & $\begin{array}{l}\mathrm{P} \\
4\end{array}$ & $\begin{array}{l}\mathrm{P} \\
5\end{array}$ & $\begin{array}{c}\mathrm{NO} \\
1 \\
\mathrm{NC} \\
1\end{array}$ & $\begin{array}{c}\mathrm{NO} \\
2 \\
\mathrm{NC} \\
2\end{array}$ & $\begin{array}{c}\mathrm{NO} \\
3 \\
\mathrm{NC} \\
3\end{array}$ & $\begin{array}{c}\mathrm{NO} \\
4 \\
\mathrm{NC} \\
4\end{array}$ & $\begin{array}{c}\mathrm{NO} \\
5 \\
\mathrm{NC} \\
5\end{array}$ & $\begin{array}{c}\mathrm{NO} \\
6 \\
\mathrm{NC} \\
6\end{array}$ & \\
\hline $7-9$ & 1 & 2 & 2 & 1 & & & 3 & 2 & 5 & 3 & & 2 & 1 & 1 & & & 19 \\
\hline $8-10$ & 2 & 1 & 2 & 2 & 1 & 1 & 1 & 2 & 1 & & & 1 & & 1 & & & 28 \\
\hline $\begin{array}{c}10 \& \\
\text { above }\end{array}$ & & & 1 & & 1 & & 1 & 2 & & & 0 & & & & & & 7 \\
\hline
\end{tabular}

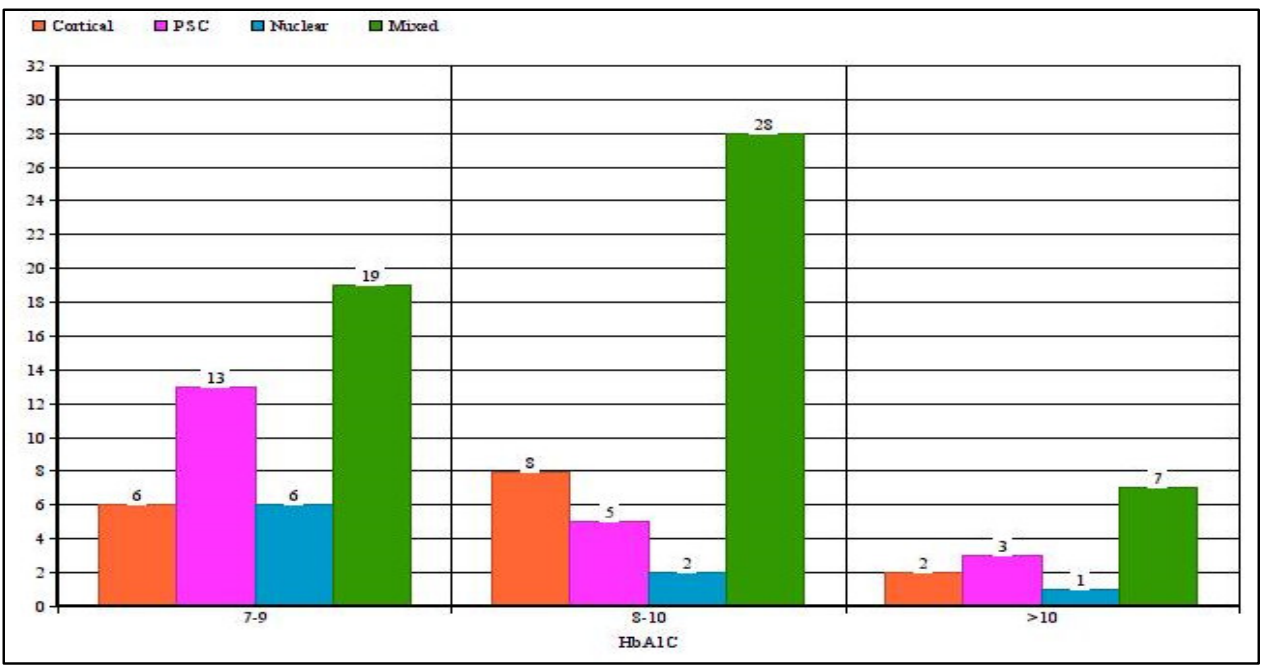

Figure 2: Frequency of cataract morphology with respect to HbA1c levels 


\section{Discussion}

Association of senile lenticular changes in type 2 diabetes mellitus has been well documented. Moreover there are quite a number of studies which suggest about high frequency of occurrence of cataracts in diabetic population $[19,20]$. The number of people with diabetes mellitus is increasing and cataracts are one of the most common causes of visual impairment in these cases.

Whereas diabetic cataract is seen in young population with type 1 diabetes is less frequent, the most frequent seen type of cataract in diabetic population is age related or senile variety. The association of diabetes with cataract can be ascribed to the excess of sorbitol formed from the accumulated high blood glucose level in the diabetic patients.

Therefore, patients with diabetes are 2-5 times more likely to develop cataracts when compared with the non-diabetic counterparts. Various studies have suggested that nuclear sclerosis is the most common type of cataract in senile population [21,22,23]. However in diabetes, results vary, according to some studies incidence of nuclear sclerosis is high as compared to cortical in type 2 diabetics whereas few studies suggest the significant elevation of cortical and posterior subcapsular cataracts in type 2 diabetes mellitus and one study mixed cataracts were more common [24-29].

The data from two population-based studies - the Beaver Dam Eye Study, the Blue Mountains Eye Study have shown an association between diabetes and posterior subcapsular cataract. Comparison has also been done on prevalence of cataracts in insulin and noninsulin dependent diabetes in which it has been found that frequency of cataractous changes are high in type 2 diabetes [30].

In the present study emphasis was made to correlate the grades of cataract with duration of diabetes and $\mathrm{HbAlc}$ levels. The prevalence of mixed cataracts were high than the monotype however it was not statistically significant. Duration of diabetes is an important risk factor for cataracts and a study had shown its significant correlation with presence of cataracts [31]. In the present study however duration of diabetes is not statistically correlated with grades of cataracts.

\section{Conclusion}

Out of 100 eyes, 21 eyes with posterior subcapsular cataract , 16 eyes with cortical , 9 eyes with nuclear, 54 eyes with mixed component and out of 54 eyes, 34 eyes with both ns and psc component and 20 eyes with both ns and cortical component. Thirty eight patients had bilateral cataract.

In this study it was found that duration of non-isulin dependent diabetes mellitus and $\mathrm{HbA1C}$ levels are not statistically correlated with the grades of cataract. Mixed cataracts were however more common than any particular morphology of cataract.

\section{What this study adds to the existing knowledge?}

Cataract in diabetes is an important domain and the preoperative evaluation of patients undergoing cataract extraction has a significant role in management of postoperative complications and improving visual outcomes.

In this study morphology of cataract was categorized as per LOCS 3 protocol which is the gold standard and what was observed in the present study is that it is the mixed type of cataract which is more common than any other morphology of cataract however there is no statistical correlation between duration of NIDDM and $\mathrm{HbA} 1 \mathrm{C}$ levels with grade of cataract.

\section{Author's contribution}

Both the authors have contributed equally in collecting data regarding cataract morphology in diabetics.

Funding: Nil, Conflict of interest: Nil Permission from IRB: Yes

\section{References}

1. Khairallah M, Kahloun R, Bourne R, Limburg H, Flaxman SR, Jonas JB, et al. Number of People Blind or Visually Impaired by Cataract Worldwide and in World Regions, 1990 to 2010. Invest Ophthalmol Vis Sci. 2015; 56(11):6762-9. DOI: 10.1167/iovs.15-17201.

2. Thulasiraj RD, Nirmalan PK, Ramakrishnan R, Krishnadas R, Manimekalai TK, Baburajan NP, et al. Blindness and vision impairment in a rural south Indian population: the Aravind Comprehensive Eye Survey. Ophthalmol. 2003;110(8):1491-8. DOI:10.1016/S01616420(03)00565-7

3. Thulasiraj RD, Rahamathulla R, Saraswati A, Selvaraj S, Ellwein LB. The Sivaganga eye survey: I. Blindness and cataract surgery. Ophthalmic Epidemiol. 2002; 9(5):299-312. 
4. Nirmalan PK, Thulasiraj RD, Maneksha V, Rahmathullah R, Ramakrishnan R, Padmavathi A, et al. A population based eye survey of older adults in Tirunelveli district of south India: blindness, cataract surgery, and visual outcomes. Br J Ophthalmol. 2002; 86 (5):505-12. DOI:10.1136/bjo.86.5.505

5. Murthy GV, Gupta S, Ellwein LB, Munoz SR, Bachani D, Dada VK. A population-based eye survey of older adults in a rural district of Rajasthan: I. Central vision impairment, blindness, and cataract surgery. Ophthalmol. 2001;108(4):679-85.DOI: https://doi.org/ 10. 1016/S0161-6420(00)00579-0

6. Mohan M. National Survey of Blindness-India. NPCB-WHO Report. New Delhi: Ministry of Health and Family Welfare, Government of India; 1989

7. Mohan M. Collaborative Study on Blindness (19711974): A report. New Delhi, India: Indian Council of Medical Research; 1987;1-65.

8. Government of India Annual Report 2003-4. Ministry of Health and Family Welfare, New Delhi.

9. Neena J, Rachel J, Praveen V, Murthy GV, RAAB India Study Group. Rapid assessment of avoidable blindness in India. PloS one. 2008;3(8):e2867. DOI: https://doi.org/10.1371/journal.pone.0002867

10. Hu FB. Sedentary lifestyle and risk of obesity and type 2 diabetes. Lipids. 2003;38(2):103-8. DOI:https: //doi. org/10.1007/s11745-003-1038-4

11. Hamilton AM, Ulbig MW, Polkinghorne $P$. Epidemiology of diabetic retinopathy. In: Hamilton AM, Ulbig MW, Polkinghorne P, editors. Manag Diab Retino. London: BMJ Publishing G; 1996. pp. 1-15.

12. Klein BE, Klein R, Moss SE. Prevalence of cataracts in a population-based study of persons with diabetes mellitus. Ophthalmol. 1985;92(9):1191-6.DOI: https://doi.org/10.1016/S0161-6420(85) 33877-0

13. Klein R, Klein BE, Moss SE. Visual impairment in diabetes. Ophthalmol. 1984;91(1):1-9.DOI: https://doi. org/ 10.1016/S0161-6420(84)34337-8

14. Klein BE, Klein R, Moss SE. Incidence of cataract surgery in the Wisconsin Epidemiologic Study of Diabetic Retinopathy.Am J Ophthalmol. 1995;119(3): 295-300. DOI:10.1016/s0002-9394(14)71170-5
15. Klein BE, Klein R, Wang Q, Moss SE. Older-onset diabetes and lens opacities. The Beaver Dam Eye Study. Ophthalmic Epidemiol. 1995;2(1):49-55.

16. Janghorbani $M$, Amini $M$. Cataract in type 2 diabetes mellitus in Isfahan, Iran: incidence and risk factors. Ophthalmic Epidemiol. 2004; 11(5):347-58. DOI:10.1080/09286580490888753

17. Chylack LT Jr, Wolfe JK, Singer DM, Leske MC, Bullimore MA, Bailey IL, et al. The Lens Opacities Classification System III. The Longitudinal Study of Cataract Study Group. Arch Ophthalmol. 1993; 111(6): 831-6. DOI:10. 1001/archopht. 1993. 0109006011 9035

18. Tung TH, Liu JH, Lee FL, Chen SJ, Tsai CY, Chou P. Community-based study of cataracts among type 2 diabetics in Kinmen. Eur J Epidemiol. 2005; 20(5): 435-41.

19. Li L, Wan XH, Zhao GH. Meta-analysis of the risk of cataract in type 2 diabetes. BMC Ophthalmol. 2014;14:94. DOI: 10.1186/1471-2415-14-94.

20. Srinivasan S, Raman R, Swaminathan G, Ganesan S, Kulothungan V, Sharma T. Incidence, Progression, and Risk Factors for Cataract in Type 2 Diabetes. Invest Ophthalmol Vis Sci. 2017;58(13):5921-5929. DOI: $10.1167 /$ iovs.17-22264.

21. Vashist P, Talwar B, Gogoi M, Maraini G, Camparini M, Ravindran RD, et al. Prevalence of cataract in an older population in India: the India study of age-related eye disease. Ophthalmol. 2011; 118 (2): 272-8.e1-2. DOI: 10. 1016/j. ophtha. 2010. 05. 020.

22. Klein BE, Klein R, Lee KE. Incidence of agerelated cataract: the Beaver Dam Eye Study. Arch Ophthalmol. 1998; 116 (2): 219-25. DOI:10.1001/ archopht. 116.2.219

23. Congdon N, West SK, Buhrmann RR, Kouzis A, Muñoz B, Mkocha H. Prevalence of the different types of age-related cataract in an African population. Invest Ophthalmol Vis Sci. 2001;42(11):2478-82.

24. VK Lalitha, TA Ajith. Association of grade of cataract with duration of diabetes, age and gender in patients with type 2 diabetes mellitus. Int J Adv Med 2016;3(2):304-8.DOI: http://dx.doi.org/10.18203/23493933. ijam 20161080 


\section{Original Research Article}

25. SD Bandhu, YG Vabale, PP Sambarey, SS Raje. A study of morphology of cataract in western India. J Clinic Ophthalmol Res. 2015;3(2):91-93.DOI: 10.4103/ 2320-3897.156594

26. Nielsen NV, Vinding T. The prevalence of cataract in insulin-dependent and non-insulin-dependentdiabetes mellitus. Acta Ophthalmol (Copenh). 1984;62 (4):595-602.

27. F. Ederer, R. Hiller, HR Taylor. Senile lens changes and diabetes in two population studies. Am J Ophthalmol. 1981;91(3):381-395.

28. S. Saxena, P. Mitchell, and E. Rochtchina.Five-year incidence of cataract in older persons with diabetes and pre-diabetes. Ophthalmic Epidemiol. 2004; 11 (4): 271-277.
29. Raman R, Pal SS, Adams JS, Rani PK, Vaitheeswaran K, Sharma T. Prevalence and risk factors for cataract in diabetes: SankaraNethralaya Diabetic Retinopathy Epidemiology and Molecular Genetics Study, report no. 17. InvestigatOphthalmol\& Visual Sci. 2010;51(12):6253-61.DOI:10.1167/iovs. $10-5414$

30. Rowe NG, Mitchell PG, Cumming RG, Wans JJ. Diabetes, fasting blood glucose and age-related cataract: the Blue Mountains Eye Study. Ophthalmic Epidemiol. 2000;7(2):103-14.

31. Kim SI, Kim SJ. Prevalence and risk factors for cataracts in persons with type 2 diabetes mellitus. Korean J Ophthalmol. 2006;20(4):201-4. DOI:10.3341/ kjo.2006.20.4.201.

\section{How to cite this article?}

Chopra A, Sharma A. Evaluation of morphology of cataracts in patients with NIDDM. Trop J Ophthalmol Otolaryngol. 2019; 4(3):227-232.doi:10.17511/jooo.2019.i03.08 